\title{
Spatial and temporal distribution of MODIS and MISR aerosol optical depth over northern China and comparison with AERONET
}

\author{
QI YuLei, GE JinMing \& HUANG JianPing* \\ College of Atmospheric Sciences, Lanzhou University, Key Laboratory of Semi-arid Climate Change, Ministry of Education, \\ Lanzhou 730000, China
}

Received October 8, 2012; accepted December 17, 2012; published online February 27, 2013

\begin{abstract}
Aerosol optical depths (AODs) from MODIS and MISR onboard the Terra satellite are assessed by comparison with measurements from four AERONET sites located in northern China for the period 2006-2009. The results show that MISR performs better than MODIS at the SACOL and Beijing sites. For the Xianghe and Xinglong sites, MODIS AOD retrievals are better than those of MISR. Overall, the relative error of the Angstrom exponent from MISR compared with AERONET is about $14 \%$, but the MODIS error can reach 30\%. Thus, it may be better to use the MISR Angstrom exponent to derive wavelength-dependent AOD values when calculating the aerosol radiative forcing in a radiative transfer model. Seasonal analysis of AOD over most of China shows two main areas with high aerosol loading: the Taklimakan Desert region and the southern part of North China and northern part of East China. The locations of these two areas of high aerosol loading do not change with season, but the AOD values have significant seasonal variation. The largest AOD value in the Taklimakan appears in spring when the Angstrom exponents are the lowest, which means the particle radii are relatively large. Over North and East China, the highest aerosol loading appears in summer. The aerosol particles are smallest in summer over both high-AOD areas.
\end{abstract}

MODIS, MISR, AERONET, AOD, aerosol optical depth

Citation: Qi Y L, Ge J M, Huang J P. Spatial and temporal distribution of MODIS and MISR aerosol optical depth over northern China and comparison with AERONET. Chin Sci Bull, 2013, 58: 2497-2506, doi: 10.1007/s11434-013-5678-5

Aerosol, consisting of a variety of liquid and solid particles suspended in the atmosphere, is an important component of the earth-ocean-atmosphere system. Aerosol may directly impact the earth's energy budget by scattering and absorbing solar radiation, altering the radiative balance of the earth-atmosphere system, and indirectly by acting as cloud condensation nuclei and ice nuclei, thus modifying the microphysical properties and lifetime of clouds [1], and hence their radiative characteristics [2-5].

Aerosol life time can be just a few weeks or even shorter [6], and aerosol sources are distributed very unevenly, so that the spatial and temporal distribution of atmospheric aerosol is far from homogeneous [7]. Aerosol is an important component of climate models and contributes a large uncertainty to the radiative forcing of the earth-

*Corresponding author (email: hjp@1zu.edu.cn) atmosphere system [8], because of the lack of accurate longterm observations of aerosol optical characteristics and their spatial and temporal distribution.

Aerosol optical depth (AOD), which is a key measure of aerosol optical properties, is a vertical integral of the extinction coefficient, representing the attenuation of solar radiation by aerosol scattering and absorption. It can also indicate air turbidity to a certain extent, and is an important parameter in the quantitative calculation of aerosol radiative forcing. The AOD is usually obtained from ground-based and space-based observations. Ground-based observations have high temporal and spectral resolution, and relatively simple retrieval methods, but only represent a small area around the site. Satellite observations have been widely used in the study of aerosol radiative forcing on regional and global climate because of their high spatial resolution and global coverage. However, satellite-based AOD retriev- 
al algorithms are relatively complicated and are less accurate than surface observations. In order to make the best use of satellite data and reduce the uncertainty of aerosol effects on regional and global climate, satellite measurements need to be validated using ground-based observations.

The Moderate Resolution Imaging Spectroradiometer (MODIS) [9] and Multiangle Imaging SpectroRadiometer (MISR) [10] onboard the Earth Observing System (EOS) satellites have been used extensively for global aerosol observations [11]. Numerous comparisons and validations of the two satellites with the Aerosol Robotic Network (AERONET) [12] have been performed. Except in some coastal zones, the MODIS AOD retrievals over land are within the retrieval error given by $\Delta \tau_{\mathrm{a}}= \pm 0.05 \pm 0.2 \tau_{\mathrm{a}}$ [13]. Estimated errors are relatively large in Africa and Southeast Asia, and small in other areas [14]. The differences in AOD between MODIS and AERONET can vary significantly with region and season over China. Generally, they are smaller in the south and east of China than in the north and west, and smaller in dry seasons than in wet seasons $[15,16]$. At the Beijing site, MODIS-retrieved AOD correlates well with AERONET observations. When the AOD is small (0-0.5), MODIS retrievals are greater than AERONET, but are lower than AERONET when the AOD is large (0.5-1.0) [17-19]. In marine areas, MODIS AOD is generally consistent with AERONET near the East China Sea coast, but it is higher than AERONET over the coast of the Pohai Sea and the Yellow Sea regions [20,21]. Substantial improvements were found in the MODIS collection 5 AOD products relative to collection 4 products $[22,23]$.

Diner et al. [24] showed that MISR AOD has a positive bias of 0.02 and an overestimate of $10 \%$, by comparing MISR AOD and ground-based observations for the period August-September 2000 over southern Africa. Liu et al. [25] compared MISR AOD with measurements from 16 AERONET sites over America, and found that the retrieval errors of MISR AOD were within $\pm 0.04 \pm 0.18 \tau_{\mathrm{a}}$. In desert areas, MISR AOD values are consistent with the groundbased observations [26-28]. Kahn et al. [29,30] found that most MISR AOD retrievals were within either 0.05 , or $20 \%$ of the AOD, of the paired validation data from AERONET. Liu et al. [31] indicated that MISR AOD retrievals agreed well with ground-based observations for $\mathrm{AOD}<0.5$ but were systematically underestimated for AOD $>0.5$ in China.

AOD values retrieved from different satellite sensors can be quite different due to the sensor characteristics and retrieval methods. Abdou et al. [8] have shown that MODIS AOD is $35 \%$ and $10 \%$ larger than MISR AOD at $470 \mathrm{~nm}$ and $660 \mathrm{~nm}$, respectively. Zhang and Sun [32] compared monthly average AOD from MODIS and MISR with surface observations in eastern China, and found that MODIS performed better.

The underlying surface types and the aerosol spatial and temporal variability are quite complex in northern China; dust is a major component of aerosol and is widely distrib- uted in this region, resulting in problems for accurate satellite retrieval of AOD. In this paper, we carried out an intercomparison and validation of MODIS and MISR AOD and Angstrom exponent with AERONET products over northern China to better understand the accuracy and reliability of different satellite retrievals in this region for different seasons during 2005-2009. We also investigated the temporal and spatial distribution and variability of AOD and Angstrom exponent.

\section{Data}

The satellite data used in this paper are MOD04 C051 Level2 and MOD08 Level3, as well as MISR MIL2ASAE Level2 and Level3 data, covering a four-year period from December 2005 to November 2009. The satellite Level2 aerosol data are at higher resolution (10 km for MODIS, 17.6 $\mathrm{km}$ for MISR) and are used for comparison with groundbased observations. Level3 data are used to characterize spatial and seasonal distributions of aerosol and have resolution of $1^{\circ} \times 1^{\circ}$ and $0.5^{\circ} \times 0.5^{\circ}$ for MODIS and MISR, respectively.

The surface sun photometer employed by the AERONET has a very narrow field of view, and is therefore rarely affected by surface reflectance and aerosol forward scattering [33]. It has high AOD-retrieval precision with an uncertainty of 0.01-0.02 [34], and is widely used to validate satellite AOD values [16]. AERONET data products have three levels: L1.0 has neither cloud screening nor quality control; L1.5 is cloud-screened data, but not quality assured; L2.0 is both cloud-screened and quality assured. In this study, we use L2.0 data from four sites: SACOL [35], Beijing, Xianghe, and Xinglong. Long-term aerosol monitoring has been carried out at these four sites. Their location and surface type are listed in Table 1.

\section{Validation and comparison of MODIS and MISR with AERONET}

We compare satellite observations with AERONET at the SACOL, Beijing, Xianghe, and Xinglong sites in northern China, in order to validate the AOD from MODIS and MISR.

Table 1 The location and surface type of four AERONET sites

\begin{tabular}{lcccc}
\hline Site & Longitude $\left({ }^{\circ} \mathrm{E}\right)$ & Latitude $\left({ }^{\circ} \mathrm{N}\right)$ & Altitude $(\mathrm{m})$ & Surface type \\
\hline SACOL & 104.137 & 35.946 & 1965 & grass \\
Beijing & 116.381 & 39.977 & 92 & city \\
Xianghe & 116.962 & 39.754 & 36 & suburb \\
Xinglong & 117.578 & 40.396 & 970 & forest \\
\hline
\end{tabular}




\subsection{Interpolation of wavelength-dependent AOD}

MISR retrieves AOD at four wavelengths centered at 446, 558, 667 and $862 \mathrm{~nm}$. MODIS AOD values are derived in three spectral bands (470, 550 and $660 \mathrm{~nm})$. The sun photometer observes aerosol at six wavelengths $(380,440,500$, 675,870 and $1020 \mathrm{~nm}$ ). There is no common wavelength for MISR, MODIS, and AERONET, so we need to interpolate AODs to the same wavelength for inter-comparison. The relation of wavelength-dependent AOD and Angstrom exponent can be expressed as [36]

$$
\tau_{\mathrm{a}}(\lambda)=\beta \lambda^{-\alpha},
$$

where $\tau_{\mathrm{a}}(\lambda)$ is the AOD at a given wavelength, $\lambda$ (in $\mu \mathrm{m}$ ), $\beta$ is the turbidity coefficient which is equal to the AOD at 1 $\mu \mathrm{m}$, and $\alpha$ is the Angstrom exponent. We interpolate the sun photometer AOD values at 440 and 675 to $550 \mathrm{~nm}$, to provide a common wavelength for both satellites and AERONET.

\subsection{Space and time coincidence criteria}

The satellite AOD is an average value over a small pixel area, and the surface-observed AOD only represents a point. We therefore need to define the criteria for collocation. The criteria for an acceptable AOD comparison at a site require that AERONET data should be available within a one-hour window centered on the MODIS and MISR overpass time, and satellite data should be available within a $0.5^{\circ} \times 0.5^{\circ}$ box (i.e. a $5 \times 5$ pixel region for MODIS and a $3 \times 3$ pixel region for MISR) centered on the AERONET site [22,23]. In order for a data point to be included in our analysis we require a minimum of two AERONET retrievals within the hour, with 5 out of 25 MODIS retrievals, and 2 out of 9 MISR retrievals within the box.

\subsection{Comparison of AOD from MODIS, MISR and AERONET}

Figures 1 and 2 show the regression results for MODIS and MISR AOD against AERONET AOD at $550 \mathrm{~nm}$ wavelength. Apart from the Xinglong site, MODIS observations lie above the $y=x$ lines in Figure 1, indicating that MODIS overestimated AOD at these three sites. The differences between MODIS and AERONET AOD are significant at the SACOL and Beijing sites with an intercept of more than 0.07. At the Xianghe site, MODIS AOD is slightly higher than the surface observation with an intercept of 0.035. At the Xinglong site, MODIS observations agree well with the ground-based observations: the correlation coefficient is 0.940 , and root mean square error is 0.061 . Comparisons of MISR AODs with those derived from AERONET are shown in Figure 2. MISR tends to systematically underestimate AOD compared with ground-based observations at the four sites. The root-mean-square error for MISR is smaller than that of MODIS at SACOL and Beijing, but larger at Xianghe and Xinglong. This may be due to the relatively smaller amounts of vegetation at SACOL and
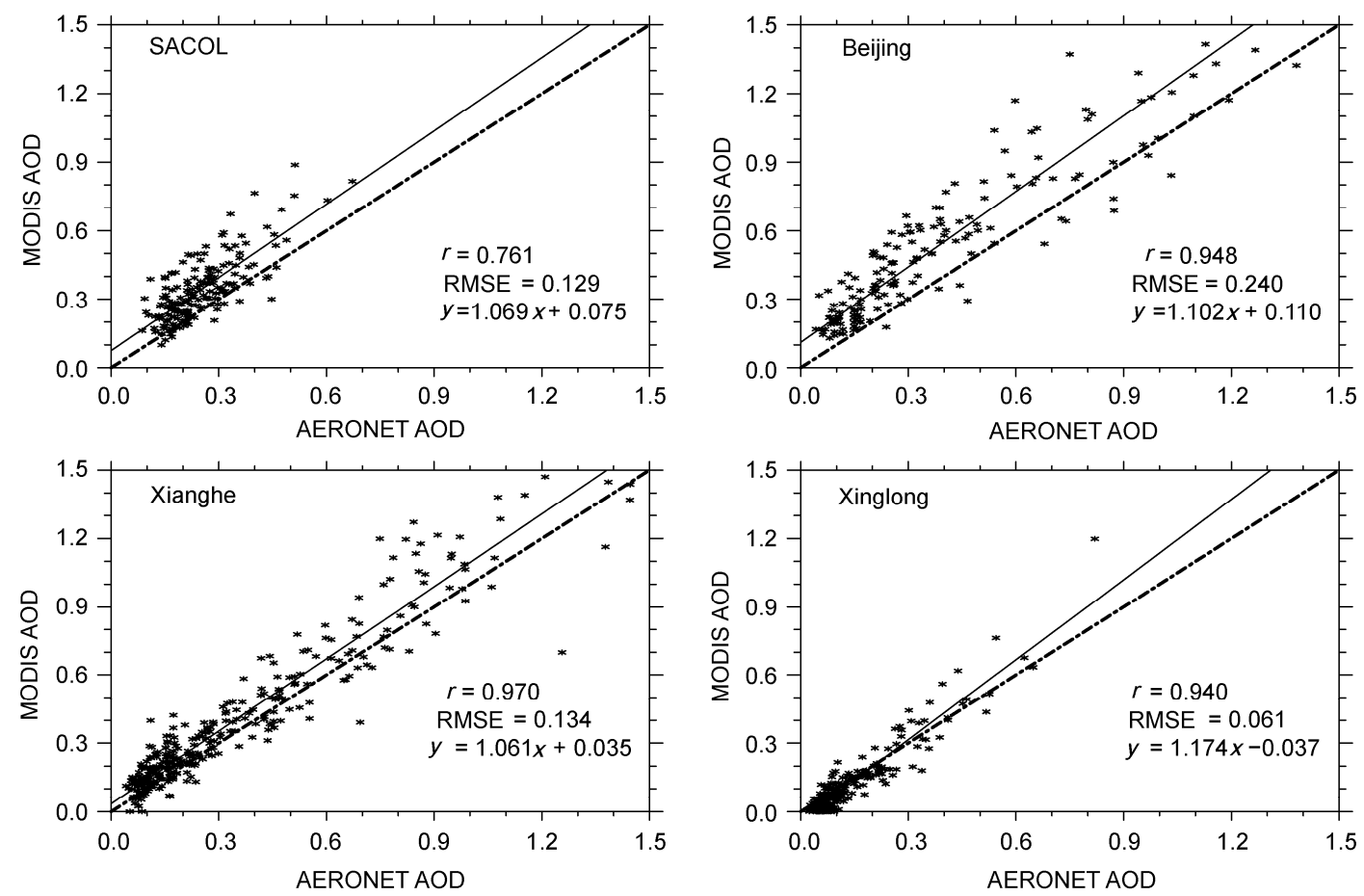

Figure 1 Scatter plots of MODIS and AERONET AOD for the four ground sites. The solid line represents the best fit $(y=m x+b)$ and the dot-dash line is the $y=x$ line. $r$ is the correlation coefficient and RMSE is the root-mean-square error. 

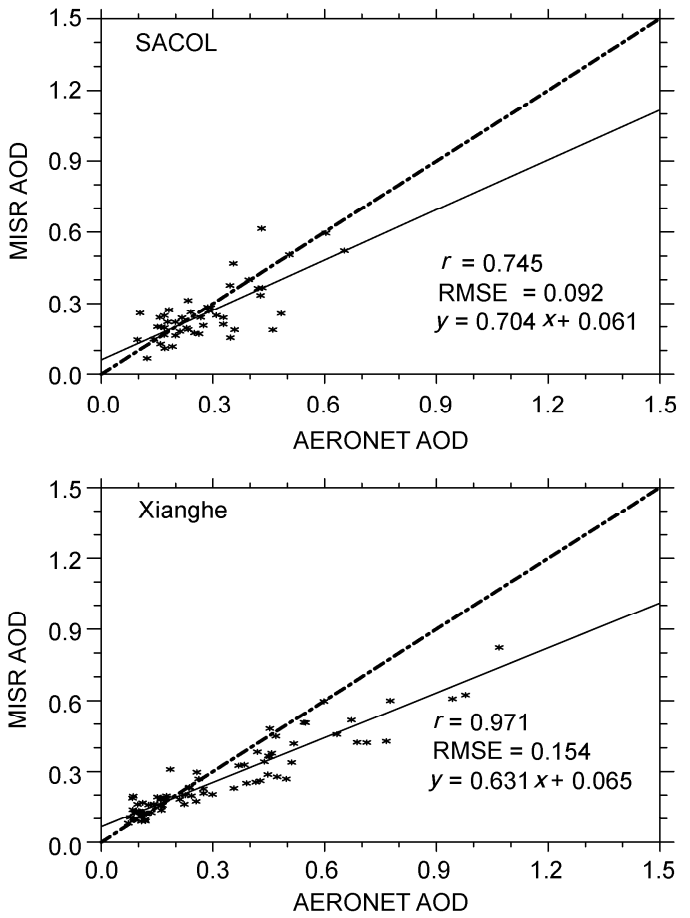

Figure 2 Same as in Figure 1 but for MISR and AERONET AOD.

Beijing, as the MODIS dark pixel algorithm may not work well over these regions. The multi-angle capability of MISR enables it to distinguish the sunlight reflected by aerosol from that reflected at the surface, and it thus performs better in AOD retrieval for the two bright regions, SACOL and Beijing. At Xianghe and Xinglong, MODIS AOD retrievals are better than those from MISR.

\subsection{Comparison of seasonally averaged AOD and Ang- strom exponent from MODIS, MISR and AERONET}

Figure 3 shows the seasonally averaged AOD from MODIS, MISR and AERONET observations. At the SACOL site, MODIS AOD is higher than that of AERONET in spring, summer, and autumn, with the largest difference $(0.13)$ in summer. MISR agrees well with surface observations with errors of less than 0.04. In winter, no MISR data can be matched with AERONET and there is only one matched point for MODIS. At the Beijing site, MODIS seasonally averaged AOD in spring and summer is 0.2 greater than that of AERONET, with relative errors higher than 50\%. In autumn and winter, MODIS AOD values are 0.07 and 0.02 higher than those from AERONET. MISR seasonally averaged AOD values are lower than the ground-observed values all the year round, with errors ranging from 0.02 (in winter) to 0.09 . At the Xianghe site, MODIS AOD is 0.14 greater than the AERONET observations in spring, and 0.06 and 0.04 greater in summer and winter, respectively. The smallest error occurs in autumn $(<0.01)$. MISR underestimates AOD by 0.02 in winter and $0.04-0.11$ in the other seasons. At the Xinglong site, MODIS AOD values are
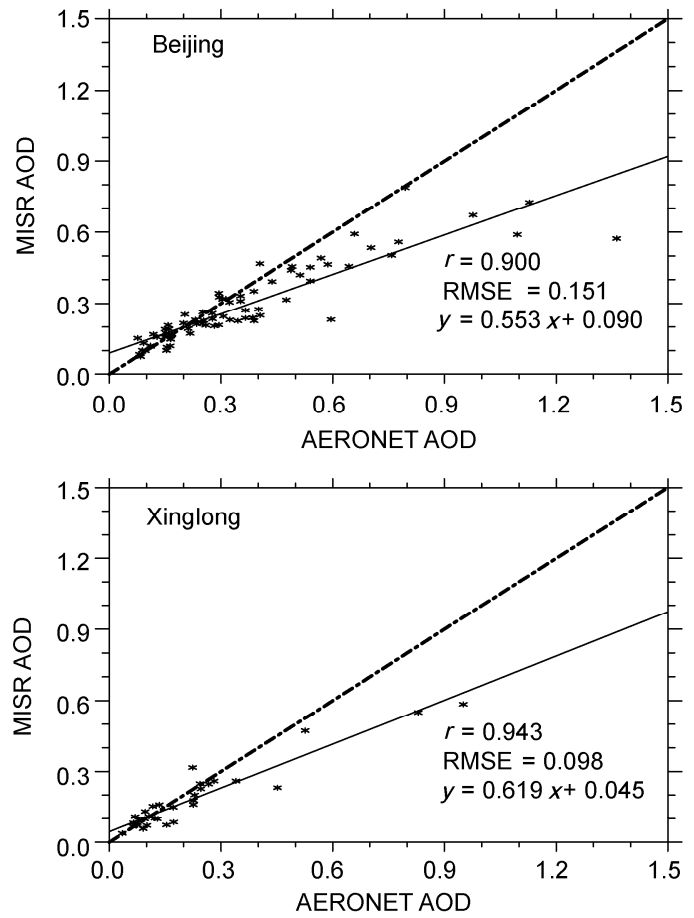

lower than ground observations for all seasons. The errors are below 0.01 in spring and winter, and are 0.06 and 0.02 in summer and autumn, respectively. MISR AOD is 0.03 smaller than that of AERONET in spring and summer, but about 0.02 and 0.01 larger in autumn and winter, respectively.

Figure 4 compares the Angstrom exponents from MODIS, MISR and AERONET observations. The Angstrom exponent can be used as an indicator of aerosol particle size: the greater the Angstrom exponent, the smaller the dominant aerosol particle in the size distribution. At the SACOL site, the Angstrom exponent values are largest in spring and smallest in summer. This may be due to the frequent dust events in spring and the high precipitation in summer [37]. In spring, the MODIS Angstrom exponent is 0.15 lower than that of AERONET, while MISR is 0.27 higher. In summer and autumn, MODIS values are 0.47 and 0.31 smaller than AERONET, corresponding to relative errors of $40 \%$ and $30 \%$, respectively, while MISR derived Angstrom exponents are 0.15 and 0.13 higher than those from AERONET with a relative error of $12 \%$. At the Beijing site, the seasonal variations in Angstrom exponent are similar to SACOL. MODIS Angstrom exponents are lower than those of AERONET by $0.30-0.47$, with a relative error of 25\%-39\% in spring, summer and autumn. The Angstrom exponent from MISR agrees closely with AERONET and the differences between MISR and AERONET are less than 0.16 with relative errors of less than $15 \%$ in all seasons. At the Xianghe site, MODIS derived Angstrom exponents are lower than ground values in all seasons with an annual average relative error of $33.5 \%$. The MISR Angstrom values differ only slightly from AERONET by about 0.02 and 0.06 

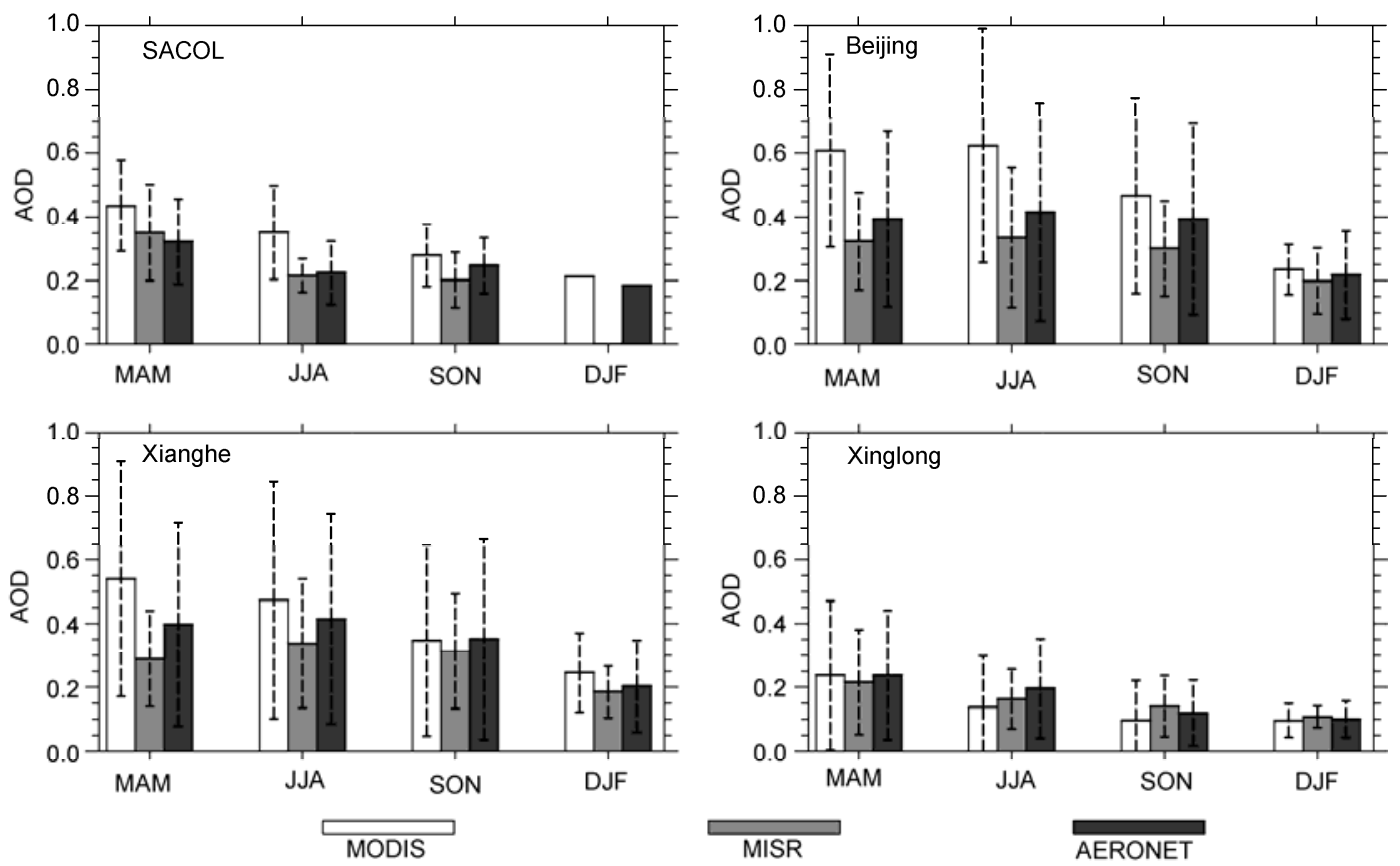

Figure 3 Comparison of seasonally averaged AOD from MODIS, MISR, and AERONET. MAM, Spring; JJA, summer; SON, autumn; DJF, winter (the same below).
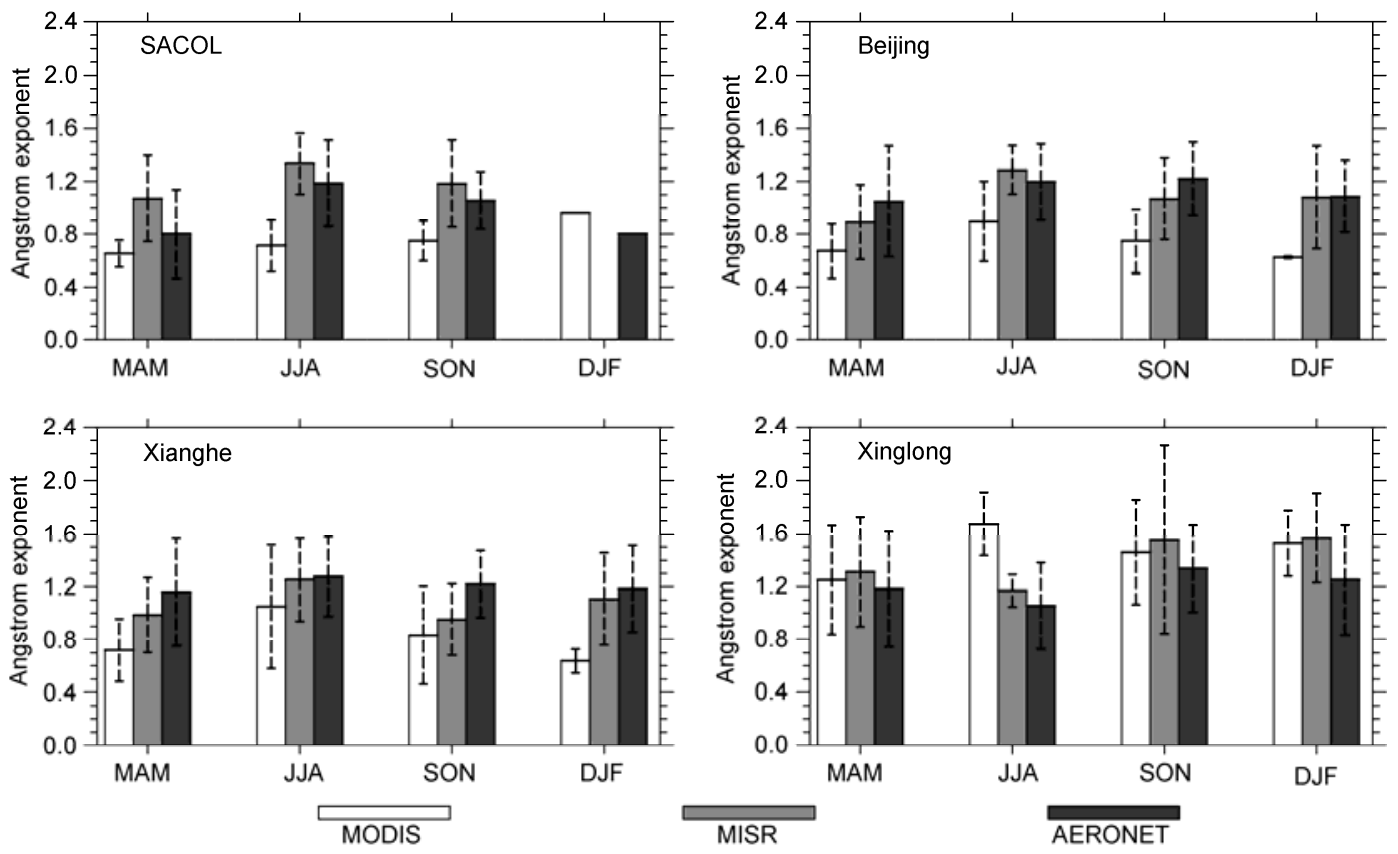

Figure 4 Same as in Figure 3 but for Angstrom exponent.

in summer and winter, respectively, and by about 0.17 and 0.26 with relative error of $15 \%$ and $22 \%$ in spring and autumn, respectively. At the Xinglong site, MODIS and MISR Angstrom exponents are higher than AERONET in all seasons. The error between MODIS and AERONET is smallest in spring (about 0.07) and largest in summer (about 0.62) with a relative error of $59 \%$. For MISR, the errors reach a minimum of 0.11 in summer and a maximum of 0.3 with relative error of $25 \%$ in winter.

Overall, the relative errors of Angstrom exponents between MODIS and AERONET are around 30\%. MISR observed Angstrom exponents are closer to ground observations with a relative error of $14 \%$. This may be due to the different methods used in MISR and MODIS for obtaining wavelength-dependent surface reflectance. It is clear that when we calculate broad-band aerosol radiative forcing in a 
radiative transfer model, if the AOD at $550 \mathrm{~nm}$ wavelength is accurate, the AOD extrapolated using the MISR Angstrom exponent at other wavelengths will be more accurate than that using MODIS.

\section{Spatial and temporal distribution of AOD and Angstrom exponent from MODIS and MISR}

\subsection{Seasonally averaged AOD distribution from MODIS and MISR during 2006-2009}

Figures 5 and 6 show the seasonally averaged AOD distributions for MODIS and MISR at $550 \mathrm{~nm}$ wavelength for 2006-2009. MODIS AOD data are not valid over most of the area north of the Hu Line [38] in all seasons, although MISR can successfully retrieve AOD in these regions. South of the $\mathrm{Hu}$ Line, the AOD distribution patterns from the two satellite sensors are consistent. High AOD values are found in the Sichuan Basin (corresponding to the location of the southwest vortex), Central China, and northern East China, and low value areas are located over the eastern Tibetan Plateau, eastern Inner Mongolia, and the northern part of Northeast China. The MISR AOD distribution also shows that AOD values are very high in the Tarim Basin, and low over the southeastern Tibetan Plateau. In low-AOD areas where both MODIS and MISR AOD values are less than 0.2, the difference between MODIS and MISR AOD is less than 0.1. Over the high AOD loading regions, the MODIS AOD values are larger than 0.7, and can be as large as 0.9 for some areas. MODIS AOD values are 0.2 greater than those from MISR.

Areas where satellite AOD retrieval breaks down are shown in white. MODIS AOD cannot be retrieved over the Tarim Basin and western Inner Mongolia. This may be
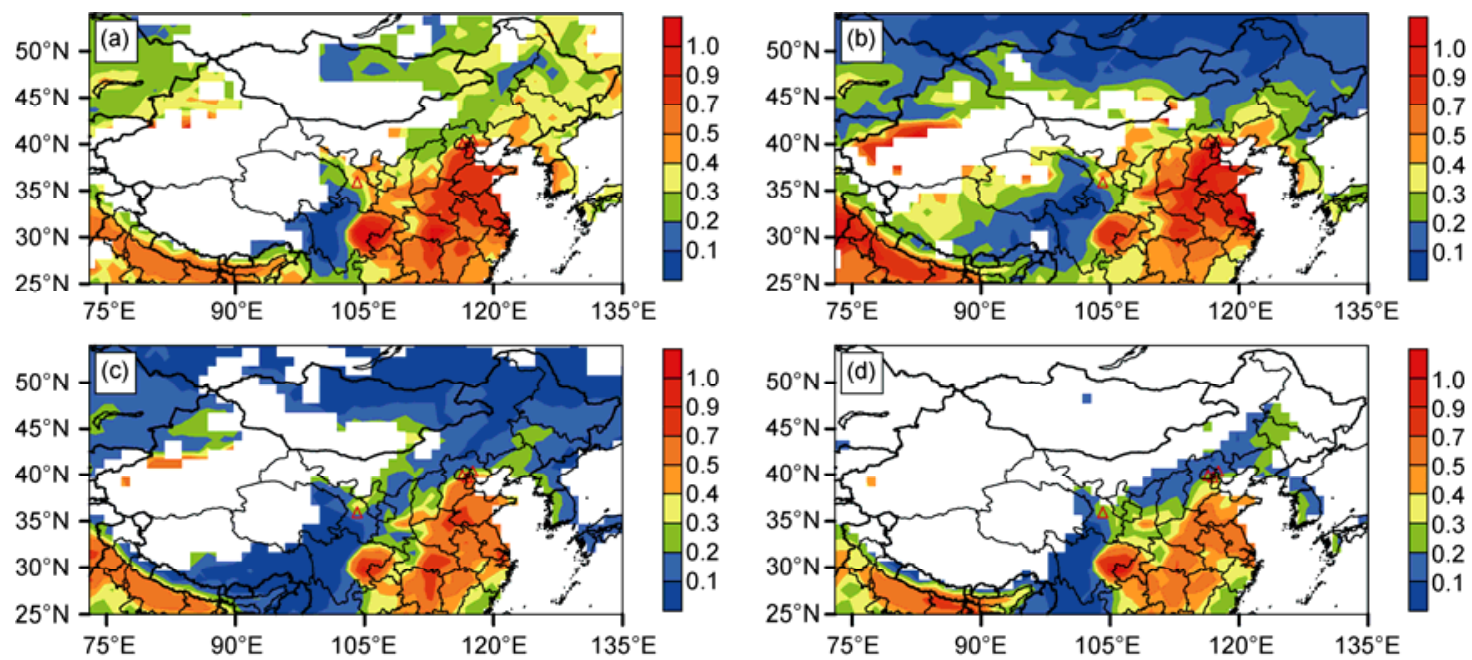

Figure 5 Seasonally averaged AOD $(550 \mathrm{~nm})$ distributions from MODIS for 2006-2009. AOD retrievals are not valid in the white regions. Red triangles represent AERONET locations. (a) Spring (MAM); (b) summer (JJA); (c) autumn (SON); (d) winter (DJF) (the same below).
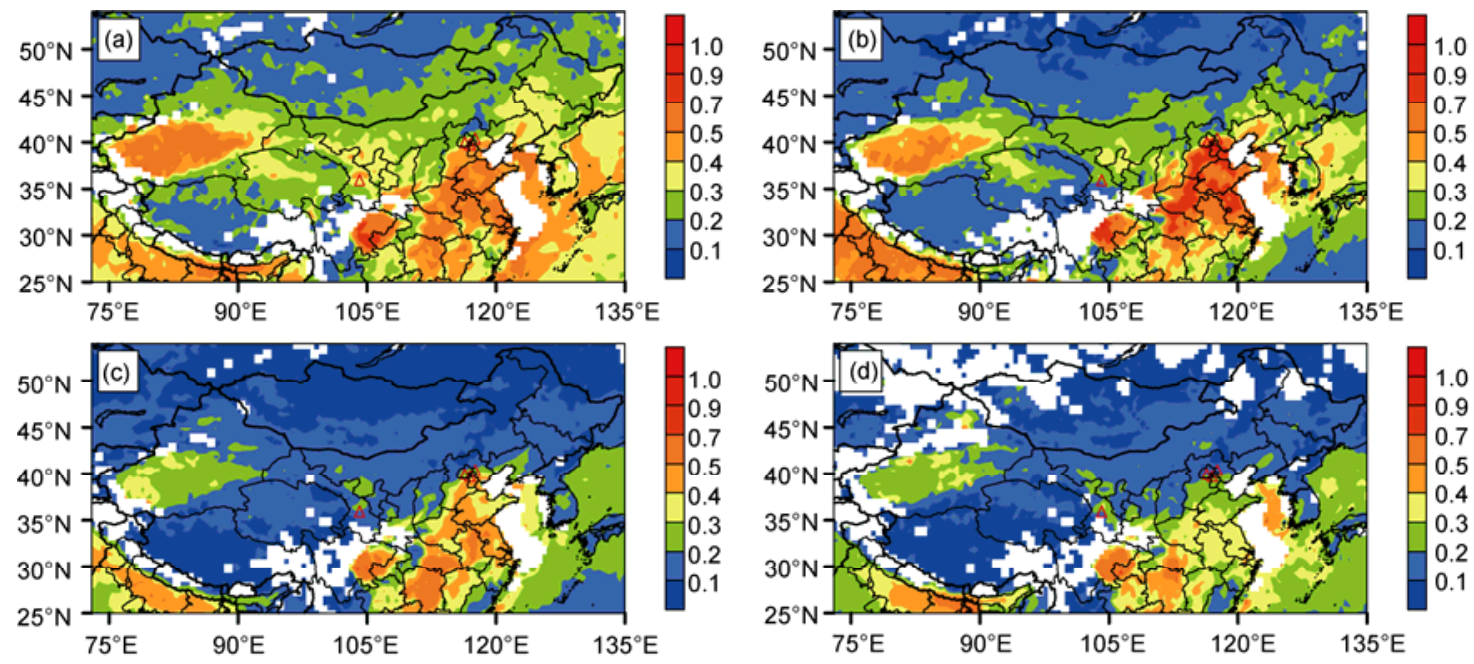

Figure 6 Same as in Figure 5 but from MISR. 
because these are desert areas with high surface albedo and the MODIS aerosol retrieval method is unable to find dark pixels with surface albedo between 0.01 and 0.24 in the $2.13 \mu \mathrm{m}$ channel [39], or because the surface albedo empirical relationship is not appropriate. MISR uses multi-angle measurements to obtain surface reflected solar radiation at visible wavelengths without any assumptions about the reflection relations among bands, and thus can successfully retrieve AOD over bright surfaces. The MISR AOD distribution clearly shows that the AOD over the Tarim Basin is significantly higher than surrounding areas. This is mainly caused by dust aerosol from the Taklimakan Desert [40,41].

In Figure 5, we can see that high-AOD areas are located in the Sichuan Basin, Central China, East China, South China, and North China. The locations of high aerosol loading areas do not change with season, but the AOD values have significant seasonal variation. The AOD values in spring and summer are 0.2 higher than in autumn and winter over southern North China and northern East China. The AOD over the Sichuan Basin and Central China only changes slightly with season. Over the eastern Tibetan Plateau, the AOD values remain as low as 0.2 throughout the year. Over eastern Inner Mongolia and northern Northeast China, the AOD values are highest in spring, when they are 0.1 higher than in summer and autumn. The area of invalid AOD data is largest in winter, and these regions are mainly located in Xinjiang, the Tibetan Plateau, northern Gansu, Inner Mongolia and most of Northeast China. The area of invalid AOD data is smaller in spring and autumn, and a minimum in summer where AOD is only unavailable over southern Xinjiang, northern Gansu, western Inner Mongolia, and a small part of Northern Qinghai. This may be caused by lower vegetation but larger snow cover [42] in winter, which may increase the surface albedo and therefore lead to the failure of MODIS AOD retrieval in these regions.

Figure 6 shows the AOD distribution observed by MISR. The AOD pattern is almost the same as MODIS. The AOD values over the Tarim Basin are 0.5-0.7 in spring, 0.4-0.5 in summer, and drop down to 0.3 in autumn and winter. This is because dust events occur frequently in spring and summer. In Central China and northern East China, the AOD values are highest (more than 0.7) in summer, and lowest (about 0.3-0.4) in winter. During spring and autumn, the values are about 0.5 . Aerosols in this region are mainly anthropogenic particles, and are influenced by the East Asian monsoon. In summer, convective turbulence may transport low-level aerosol upward to high altitude, and high humidity and temperature conditions can increase the rate of gas-particle transformation and hygroscopic growth, which will increase aerosol backward scattering [43], and thus lead to the high AOD estimated by satellite. In winter, the northern cold, dry and clean winter monsoon affects China. Diffusion conditions are good in this season, so the AOD values are small. Over the Qinghai-Tibetan Plateau,
Gansu, Inner Mongolia and northeastern regions, the AOD values are below 0.2 in autumn and winter, and around 0.3 in spring and summer.

\subsection{Seasonally averaged Angstrom exponent distribu- tion from MODIS and MISR during 2006-2009}

Figures 7 and 8 show the seasonally averaged Angstrom exponent distributions for MODIS and MISR, respectively, during 2006-2009. The high Angstrom exponent values from MODIS are found in eastern Southwest China, southwestern Central China, southern East China, eastern Inner Mongolia, and eastern Northeast China. The Angstrom exponent values over these regions are about 1.4 , and can be up to 1.6 in places. This indicates that the aerosols are mainly small particles. The low Angstrom exponent value areas are mainly located in northern Xinjiang, the western Tibetan Plateau, Ningxia, and central Inner Mongolia. The mean value is about 0.6 , indicating that aerosols in those areas are mainly large particles. MISR high Angstrom exponent value areas are mainly located in eastern Inner Mongolia and northeastern regions with mean value about 1.4. Low Angstrom exponent areas are in the Tarim Basin and western Inner Mongolia with an average value of 0.5. The low Angstrom exponent areas of MODIS and MISR are both located in the Taklimakan and Tengger Deserts, where dust particles are the main component of aerosol. The high Angstrom exponent areas correspond to areas of considerable human activity where the aerosols are mainly small anthropogenic particles.

In Figure 7, we can see that the MODIS Angstrom exponent is largest in summer. The values in autumn are larger than those of spring, and the minimum values are in winter. In central China, northern East China, and southern North China, average Angstrom exponents are about 1.2 in summer, 1.0 in autumn, and 0.8 in spring. The lowest value $(<0.7)$ occurs in winter. A comparison with the AOD distributions in Figure 5 shows that although AOD values are larger in summer, the Angstrom values are relatively large, indicating that aerosol particles are small. We may infer that the summer monsoon precipitation scavenges larger particles out of the low atmosphere layer but leaves particles with smaller radii in the upper troposphere through strong vertical convection in this season [44]. Gas-particle transformation may be also strong and secondary anthropogenic aerosols significantly increased, resulting in large Angstrom exponents in summer.

Figure 8 shows that in the Tarim Basin, MISR-derived Angstrom exponents are largest in summer with a mean value of 0.7. In other seasons, Angstrom exponent values are under 0.6 and do not vary much with season. Combining Figures 6 and 8, we can see that although AOD values are larger over the Taklimakan Desert in summer, particle radii are smaller than in spring. Thus, we may infer that the strong summer heating-driven convection over the Taklimakan 

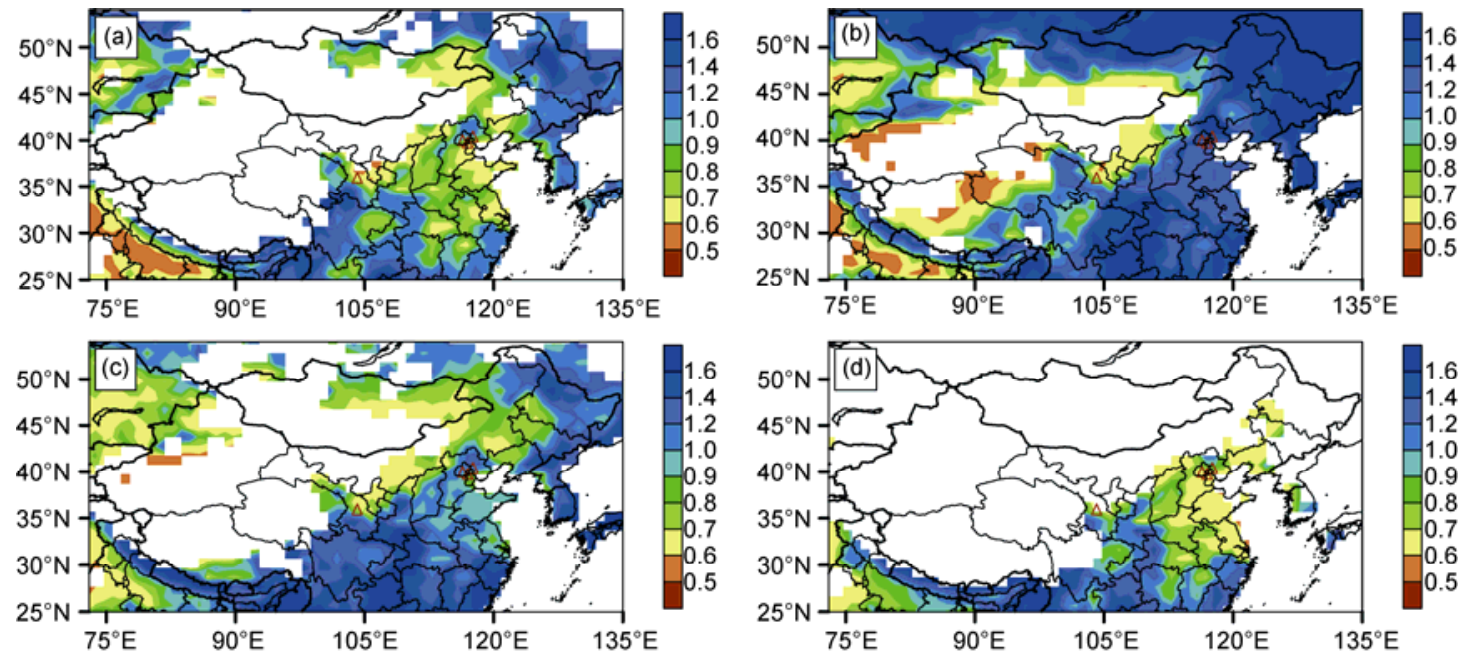

Figure 7 Seasonally averaged Angstrom exponent distributions from MODIS for 2006-2009. (a) Spring (MAM); (b) summer (JJA); (c) autumn (SON); (d) winter (DJF) (the same below).
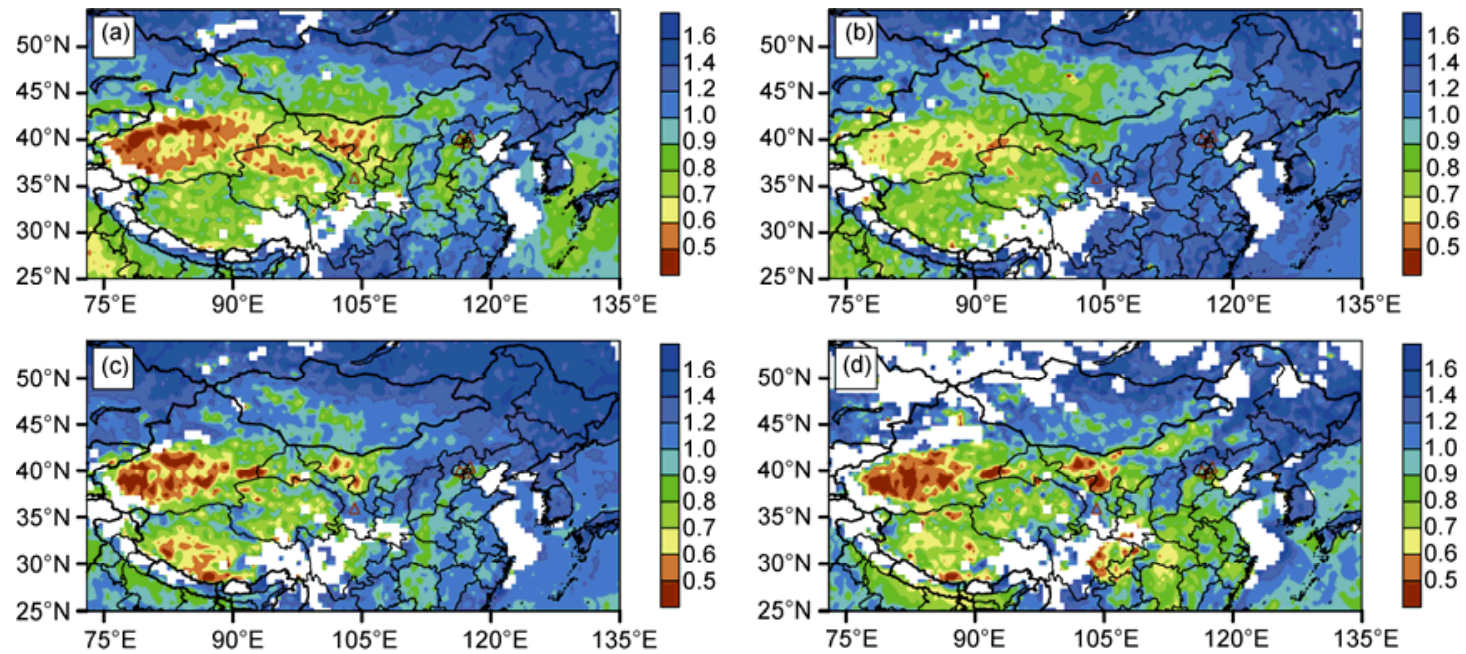

Figure 8 Same as in Figure 7 but from MISR.

Desert [45] can only maintain relatively smaller particles in the atmosphere, but in spring and winter the strong wind can carry relatively large particles into the atmosphere. Over the southwest Tibetan Plateau the minimum Angstrom exponents appear in autumn with a mean value of 0.6. In northwest Qinghai, the minimum value is about 0.5 in spring. In Central China, northern East China and southern North China, Angstrom exponent values are smallest in winter (about 0.8), and largest (about 1.2) in summer. In eastern Inner Mongolia and North China Angstrom exponents are around 1.2 and do not significantly change with season.

In Central China, southern North China, and northern East China, both MODIS and MISR Angstrom exponents are smaller in winter and spring and larger in summer and autumn. Thus aerosol particle sizes in these areas are larger in winter and spring than in summer and autumn. In winter and spring, sandstorms frequently occur in northwest China and dust particles can be transported to these downwind regions, with the large dust particles accounting for the small Angstrom exponent. In summer, East Asian monsoon effects may lead to smaller particle radii.

\section{Conclusions}

We compared MODIS and MISR AOD values with those from four AERONET sites. At the SACOL and Beijing sites, MISR performs better AOD retrievals than MODIS. At the Xianghe and Xinglong sites, MODIS AOD is more accurate than MISR. The mean relative error of the Angstrom exponent is $14 \%$ for MISR, and 30\% for MODIS. MISR Angstrom exponents are more consistent with AERONET observations. 
MODIS AOD retrievals are not available north of the $\mathrm{Hu}$ Line [38], but MISR succeeds in retrieving AOD in these areas. High MODIS and MISR AOD values are found in Xinjiang, the Tarim Basin, Sichuan Basin, Central China, and northern East China. Low values are found over the eastern Tibetan Plateau, eastern Inner Mongolia, and northern North China. Over areas with the high values, MODIS AOD is 0.2 larger than MISR, while the averaged difference between MODIS and MISR is less than 0.1 in low value areas. The pattern of AOD distribution does not significantly vary with season, but the AOD values have apparent seasonal variations. AOD values over the Tarim Basin reach their maximum value in spring, while in southern North China and northern East China, the maximum AOD appears in summer.

The MODIS Angstrom exponent distributions indicate that aerosols are composed mainly of small particles in eastern Southwest China, southwestern Central China, eastern Northeast China, eastern Inner Mongolia, and southern East China. Large particles are dominant in central Inner Mongolia, Ningxia, northern Xinjiang, the Tarim Basin, and the western Tibetan Plateau. MISR observations also indicate that aerosols in the eastern part of Inner Mongolia and Northeast China are mainly small particles. In the Tarim Basin, Inner Mongolia and western Gansu the aerosols are mainly large particles and the effective particle radii are largest in spring and smallest in summer. In southern North China, Central China and northern East China, larger particles dominate in winter and spring, and smaller particles in summer.

We thank Professor Huang Jianping, and researchers Chen Hongbin and Wang Pucai, as well as their research team members, who contributed to the establishment and maintenance of the SACOL, Beijing, Xianghe, and Xinglong sites. We also thank the NASA Atmospheric Data Center and the Goddard Center for providing MISR/MODIS satellite data. This work was supported by the National Basic Research Program (2012CB955302), the National Natural Science Foundation of China (41105019 and 41175042), the Specialized Research Fund for Doctoral Program of Higher Education (20110211120021), and the Fundamental Research Fund for Central Universities (lzujbky-2011-4).

1 Lu G X, Guo X L. Distribution and origin of aerosol and its transform relationship with $\mathrm{CCN}$ derived from the spring multi-aircraft measurements of Beijing Cloud Experiment (BCE). Chin Sci Bull, 2012, 57: 2460-2469

2 Andrews E, Ogren J A, Bonasoni P, et al. Climatology of aerosol radiative properties in the free troposphere. Atmos Res, 2011, 102: 365-393

3 Huang J, Wang Y, Wang T, et al. Dusty cloud radiative forcing derived from satellite data for middle latitude regions of East Asia. Prog Nat Sci, 2006, 16: 1084-1089

4 Huang J, Lin B, Minnis P, et al. Satellite-based assessment of possible dust aerosols semi-direct effect on cloud water path over East Asia. Geophys Res Lett, 2006, 33, doi: 10.1029/2006GL026561

5 Huang J, Minnis P, Lin B, et al. Possible influences of Asian dust aerosols on cloud properties and radiative forcing observed from MODIS and CERES. Geophys Res Lett, 2006, 33: L06824

6 Ramanathan V, Crutzen P J, Kiehl J T, et al. Aerosols, climate, and the hydrological cycle. Science, 2001, 294: 2119-2124
7 Haywood J, Boucher O. Estimates of the direct and indirect radiative forcing due to tropospheric aerosols: A review. Rev Geophys, 2000, 38: 513-543

8 Abdou W A, Diner D J, Martonchik J V, et al. Comparison of coincident multiangle imaging spectroradiometer and moderate resolution imaging spectroradiometer aerosol optical depths over land and ocean scenes containing aerosol robotic network sites. J Geophys Res, 2005, 110, doi: 10.1029/2004JD004693

9 Salomonson V V, Barnes W L, Maymon P W, et al. MODIS: Advanced facility instrument for studies of the earth as a system. IEEE Trans Geosci Remote Sens, 1989, 27: 145-153

10 Diner D J, Beckert J C, Reilly T H, et al. Multi-angle imaging spectroradiometer (MISR)-Instrument description and experiment overview. IEEE Trans Geosci Remote Sens, 1998, 36: 1072-1087

11 Xiao N, Shi T, Calder C A, et al. Spatial characteristics of the difference between MISR and MODIS aerosol optical depth retrievals over mainland Southeast Asia. Remote Sens Environ, 2009, 113: 1-9

12 Holben B N, Eck T F, Slutsker I, et al. AERONET-A federated instrument network and data archive for aerosol characterization. Remote Sens Environ, 1998, 66: 1-16

13 Chu D A, Kaufman Y J, Ichoku C, et al. Validation of MODIS aerosol optical depth retrieval over land. Geophys Res Lett, 2002, 29, doi: 10.1029/2001GL013205

14 Xia X A. Significant overestimation of global aerosol optical thickness by MODIS over land. Chin Sci Bull, 2006, 51: 2297-2303

15 Wang L L, Xin J Y, Wang Y S, et al. Validation of MODIS aerosol products by CSHNET over China. Chin Sci Bull, 2007, 52: 17081718

16 Li X J, Zhang P, Zhang X Y, et al. Validation of aerosol optical thickness product over China with MODIS data operated at NSMC (in Chinese). J Appl Meteorol Sci, 2009, 20: 147-156

17 Mao J T, Li C C, Zhang J H, et al. The comparison of remote sensing aerosol optical depth from MODIS data and ground sunphotometer observations (in Chinese). J Appl Meteorol Sci, 2002, 13(Suppl): 127-135

18 Li C C, Mao J T, Liu Q H, et al. Characteristics of distribution and seasonal variation of aerosol optical depth in eastern China with MODIS products. Chin Sci Bull, 2003, 48: 2488-2495

19 Zhu A H, Li C C, Liu G Q, et al. Validation and application of MODIS remote aerosol information in Beijing (in Chinese ). Acta Sci Circum, 2004, 24: 86-90

20 Chen B Q, Yang Y M. Validation of MODIS aerosol optical thickness in the Taiwan Strait and its circumjacent sea area (in Chinese). Acta Oceanol Sin, 2005, 27: 172-178

21 Dong H Y, Liu Y, Guan Z Y. Validation of MODIS aerosol optical depth retrievals over East China Sea (in Chinese). J Nanjing Inst Meteorol, 2007, 30: 328-337

22 Mi W, Li Z, Xia X, et al. Evaluation of the moderate resolution imaging spectroradiometer aerosol products at two aerosol robotic network stations in China. J Geophys Res, 2007, 112, doi: 10.1029/2007 JD008474

23 Li Z, Niu F, Lee K H, et al. Validation and understanding of moderate resolution imaging spectroradiometer aerosol products (C5) using ground-based measurements from the handheld sun photometer network in China. J Geophys Res, 2007, 112, doi: 10.1029/2007JD008479

24 Diner D J, Abdou W A, Bruegge C J, et al. MISR aerosol optical depth retrievals over southern Africa during the SAFARI-2000 dry season campaign. Geophys Res Lett, 2001, 28: 3127-3130

25 Liu Y, Sarnat J A, Coull B A, et al. Validation of multiangle imaging spectroradiometer (MISR) aerosol optical thickness measurements using aerosol robotic network (AERONET) observations over the contiguous United States. J Geophys Res, 2004, 109, doi:10.1029/ 2003JD003981

26 Martonchik J V, Diner D J, Kahn R, et al. Comparison of MISR and AERONET aerosol optical depths over desert sites. Geophys Res Lett, 2004, 31, doi:10.1029/2004GL019807

27 Christopher S A, Wang J. Intercomparison between multi-angle imaging spectroradiometer (MISR) and sunphotometer aerosol optical thickness in dust source regions over China: Implications for satellite 
aerosol retrievals and radiative forcing calculations. Tellus Ser B, 2004, 56: 451-456

28 Ge J M, Su J, Ackerman T P, et al. Dust aerosol optical properties retrieval and radiative forcing over northwestern China during the 2008 China-U.S joint field experiment. J Geophys Res, 2010, 115, doi: 10.1029/1009JD013263

29 Kahn R A, Gaitley B J, Martonchik J V, et al. Multiangle imaging spectroradiometer (MISR) global aerosol optical depth validation based on 2 years of coincident aerosol robotic network (AERONET) observations. J Geophys Res, 2005, 110, doi: 10.1029/2004JD004706

30 Kahn R A, Gaitley B J, Garay M J, et al. Multiangle imaging spectroradiometer global aerosol product assessment by comparison with the aerosol robotic network. J Geophys Res, 2010, 115, doi: 10.1029/ 2010JD014601

31 Liu J, Xia X, Li Z, et al. Validation of multi-angle imaging spectroradiometer aerosol products in China. Tellus Ser B, 2010, 62: 117124

32 Zhang Y, Sun Z B. Comparison of MODIS and MISR aerosol optical thickness over east-central China (in Chinese). Sci Meteorol Sin, 2010, 30: 48-54

33 Ge J M, Su J, Fu Q, et al. Dust aerosol forward scattering effects on ground-based aerosol optical depth retrievals. J Quant Spectro Radiat Transfer, 2011, 112: 310-319

34 Xia X A, Chen H B, Wang P C. Validation of MODIS aerosol retrievals and evaluation of potential cloud contamination in East Asia. J Environ Sci, 2004, 16: 832-837

35 Huang J P, Zhang W, Zuo J Q, et al. An overview of the semi-arid climate and environment research observatory over the Loess Plateau.
Adv Atmos Sci, 2008, 25: 1-16

36 Eck T F, Holben B N, Reid J S, et al. Wavelength dependence of the optical depth of biomass burning, urban and desert dust aerosols. J Geophys Res, 1999, 104: 31333-31349

37 Bi J R, Huang J P, Fu Q, et al. Toward characterization of the aerosol optical properties over Loess Plateau of northwestern China. J Quant Spectro Radiat Transfer, 2011, 112: 346-360

$38 \mathrm{Hu} \mathrm{H} \mathrm{Y}$. The distribution, regionalization and prospect of China's population (in Chinese). Acta Geogr Sin, 1990, 45: 139-145

39 Remer L, Kaufman Y, Tanre D, et al. The MODIS aerosol algorithm, products and validation. J Atmos Sci, 2005, 62: 947-973

40 Yan H, Jiao M Y, Bi B G, et al. Observation on sand dust aerosol in center of Taklimakan Desert (in Chinese). J Desert Res, 2006, 26: 389-393

41 Huang J P, Minnis P, Yi Y H, et al. Summer dust aerosols detected from CALIPSO over the Tibetan Plateau. Geophys Res Lett, 2007, 34, doi:10.1029/2007GL029938

42 Liu Y B, Ju W M, Chen J M, et al. Spatial and temporal variations of forest LAI in China during 2000-2010. Chin Sci Bull, 2012, 57: 2846-2856

43 Xia X, Chen H, Wang P, et al. Variation of column-integrated aerosol properties in a Chinese urban region. J Geophys Res, 2006, 111, doi: 10.1029/2005JD006203

44 Duan J, Mao J T. Influence of aerosol on regional precipitation in North China. Chin Sci Bull, 2009, 54: 474-483

45 Huang J, Minnis P, Yan H, et al. Dust aerosol effect on semiarid climate over Northwest China detected from A-Train satellite measurements. Atmos Chem Phys, 2010, 10: 6863-6872

Open Access This article is distributed under the terms of the Creative Commons Attribution License which permits any use, distribution, and reproduction in any medium, provided the original author(s) and source are credited. 